\title{
Gas-Phase Meerwein Reaction of Epoxides with Protonated Acetonitrile Generated by Atmospheric Pressure Ionizations
}

\author{
Lianming Wu, David Q. Liu, and Alireza S. Kord \\ Analytical Sciences, GlaxoSmithKline, King of Prussia, Pennsylvania, USA
}

Ethylnitrilium ion can be generated by protonation of acetonitrile (when used as the LC-MS mobile phase) under the conditions of atmospheric pressure ionizations, including electrospray ionization (ESI) and atmospheric pressure chemical ionization (APCI) as well as atmospheric pressure photoionization (APPI). Ethylnitrilium ion $\left(\mathrm{CH}_{3}-\mathrm{C} \equiv \stackrel{+}{\mathrm{N} H}\right.$ and its canonical form $\left.\mathrm{CH}_{3}-\stackrel{+}{\mathrm{C}}=\mathrm{NH}\right)$ is shown to efficiently undergo the gas-phase Meerwein reaction with epoxides. This reaction proceeds by the initial formation of an oxonium ion followed by three-to-five-membered ring expansion via an intramolecular nucleophilic attack to yield the Meerwein reaction products. The density functional theory (DFT) calculations at the B3LYP/6-311+G(d,p) level show that the gas-phase Meerwein reaction is thermodynamically favorable. Collision-induced dissociation (CID) of the Meerwein reaction products yields the net oxygen-by-nitrogen replacement of epoxides with a characteristic mass shift of $1 \mathrm{Da}$, providing evidence for the cyclic nature of the gas-phase Meerwein reaction products. The gas-phase Meerwein reaction offers a novel and fast LC-MS approach for the direct analysis of epoxides that might be of genotoxic concern during drug development. Understanding and utilizing this unique gas-phase ion/molecule reaction, the sensitivity and selectivity for quantitation of epoxides can be enhanced. (J Am Soc Mass Spectrom 2010, 21, 1802-1813) (C) 2010 American Society for Mass Spectrometry

G as-phase ion/molecule reactions are fast, efficient, and highly sensitive to the fine structural variations such as relative positions of functional groups. Their product distributions often provide diagnostic information for structural characterization of both reactant ions and neutral molecules [1-4]. Ion/ molecule reactions have also contributed significantly to the elucidation of organic reaction mechanisms, helping to bridge the gap between gas-phase ion chemistry and condensed-phase organic chemistry. It also provides access to key properties and intrinsic reactivities of a great variety of solvent- and counterion-free gaseous ions and, as such, constitutes a powerful tool for chemical studies. Many classic organic reactions have been studied in the gas phase using the mass spectrometric methods [5-14]. Recently, with the advent of electrospray ionization (ESI) and atmospheric pressure chemical ionization (APCI), mass spectrometry has been widely used as an analytical tool for the study of atmospheric pressure ion/molecule reactions. These gas-phase reactions can even yield detailed information regarding the individual reaction step of the catalytic cycles, and thus allow the study of transient

Address reprint requests to Dr. L. Wu, Analytical Sciences, GlaxoSmithKline, 709 Swedeland Road, King of Prussia, PA 19406, USA. E-mail: lianming. 2.wu@gsk.com intermediates that have not been accessible previously by the condensed-phase techniques $[15,16]$.

Epoxides are common reagents or key intermediates in a wide variety of synthetically important condensedphase reactions, including asymmetric synthesis via the opening of the oxirane ring [17-19]. For example, Meerwein first reported his eponymous reaction in 1955 as a ring-expansion reaction occurring in a solution of epoxides and esters in the presence of $\mathrm{BF}_{3}$ (Scheme 1) [20].

In the gas phase, the Meerwein reaction with epoxides is found to be one of the most favored reactions of gaseous acylium ions (Scheme 2). The reaction proceeds by an initial O-acylation followed by an intramolecular nucleophilic attack. This results in three-to-fivemembered ring expansion to yield cyclic 1,3-dioxolanylium ions [21-23]. This structure-selective reaction, which displays many features common to those of transacetalization reactions of acylium ions with acetals and analogs [1], has been demonstrated to be very useful for both characterization and selective screening of specific compounds such as warfare agents [24].

Some epoxides are considered to be genotoxic [25] since they can form DNA adducts [26]. The regulatory agencies pay increasing attention to genotoxic impurities (GTIs), including epoxides in pharmaceuticals, requiring their control to the low parts per million (ppm) levels [27]. Based on thresholds of toxicologic concern of GTIs during drug development, testing potential 


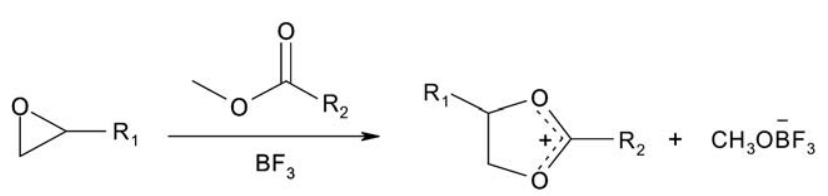

Scheme 1. Solution-phase Meerwein reaction of epoxides with esters.

GTIs, such as epoxides at ppm levels, demand for sensitive and specific methods. In this paper, we report the gas-phase Meerwein reaction of several epoxides with ethylnitrilium ion (by protonation of acetonitrile) generated in the atmospheric pressure ionization (API) sources and the application of these in-source reaction products as a novel approach to the sensitive and selective analysis of epoxides.

\section{Experimental}

\section{Chemicals}

Four epoxides in this study are listed in Figure 1. Epoxide I ((R)-2-((5-bromo-2,3-difluorophenoxy)methyl)oxirane), II ((2R,2' $\mathrm{R})-2,2^{\prime}$-(5-bromo-2-fluoro-1,3-phenylene) bis(oxy)bis(methylene)dioxirane) and IV (2-((S)-1-((R)oxiran-2-yl)allyl)isoindoline-1,3-dione) were synthesized at GalxoSmithKline (King of Prussia, PA, USA). Epoxide III ((R)-2-(chloromethyl)oxirane), formic acid ( $99.0 \%$ purity), and deuterium oxide (deuterated water, 99\% deuterium atom) were purchased from SigmaAldrich Chemical Co. (Milwaukee, WI, USA) and used without further purification. A solution of $0.01 \mathrm{M}$ sodium formate was supplied by Waters Corporation (Milford, MA, USA). The HPLC-grade solvents including water $\left(\mathrm{H}_{2} \mathrm{O}\right)$, acetonitrile $\left(\mathrm{CH}_{3} \mathrm{CN}\right)$ and methanol $\left(\mathrm{CH}_{3} \mathrm{OH}\right)$ were purchased from Burdick and Jackson (Morristown, NJ, USA).

\section{HPLC Separation Conditions}

The chromatographic separation was achieved using a Luna C18 column $(50 \times 2.0 \mathrm{~mm}, 3 \mu \mathrm{m}$; Phenomenex, Torrance, CA, USA) with a column temperature kept at $40{ }^{\circ} \mathrm{C}$. Mobile phases A and B are $0.1 \%$ formic acid (FA) in water and $0.1 \% \mathrm{FA}$ in acetonitrile, respectively. The HPLC gradient was ramped from $25 \%$ B to $75 \%$ B linearly in $4 \mathrm{~min}$. When performing the hydrogen/ deuterium $(\mathrm{H} / \mathrm{D})$ exchange experiments, $0.1 \% \mathrm{FA}$ in deuterated water $\left(\mathrm{D}_{2} \mathrm{O}\right)$ was used replacing mobile phase A [28]. The mobile phase flow rate was set at 1 $\mathrm{mL} / \mathrm{min}$, of which $250 \mu \mathrm{L} / \mathrm{min}$ was split into the API source of a mass spectrometer by an Acurate splitter (LC Packings, Sunnyvale, CA, USA).

\section{Accurate MS and $M S^{2}$ Analysis on a Q-TOF Mass Spectrometer}

The exact mass measurements and $\mathrm{MS}^{2}$ experiments were performed on a Q-TOF Premier quadrupole orthogonal acceleration time-of-flight mass spectrometer with LockSpray controlled by MassLynx 4.1 software (Waters Corporation, Manchester, UK). The ESI source was operated in the positive ion mode with a spray voltage of $-3.5 \mathrm{kV}$, the source and desolvation gas temperatures of 120 and $300^{\circ} \mathrm{C}$, an argon collision gas flow rate of $0.45 \mathrm{~mL} / \mathrm{min}$ in the T-Wave guide Mark II collision cell, a collision energy of $12-20 \mathrm{eV}$ for the collision-induced dissociation (CID) experiments, a desolvation gas flow rate of $600 \mathrm{~L} /$ hour, and a sample cone voltage of $30 \mathrm{~V}$. The LockSpray source was operated under identical conditions except with a flow rate at $3 \mu \mathrm{L} / \mathrm{min}$ for infusion of a leucine-enkephalin (LeuEnk) solution. For the APCI source, the corona discharge needle voltage was set to $-3 \mathrm{kV}$. For the atmospheric pressure photoionization (APPI) source, the Krypton (Kr) lamp was used to generate $10.6 \mathrm{eV}$ photons. The Q-TOF instrument was calibrated with a

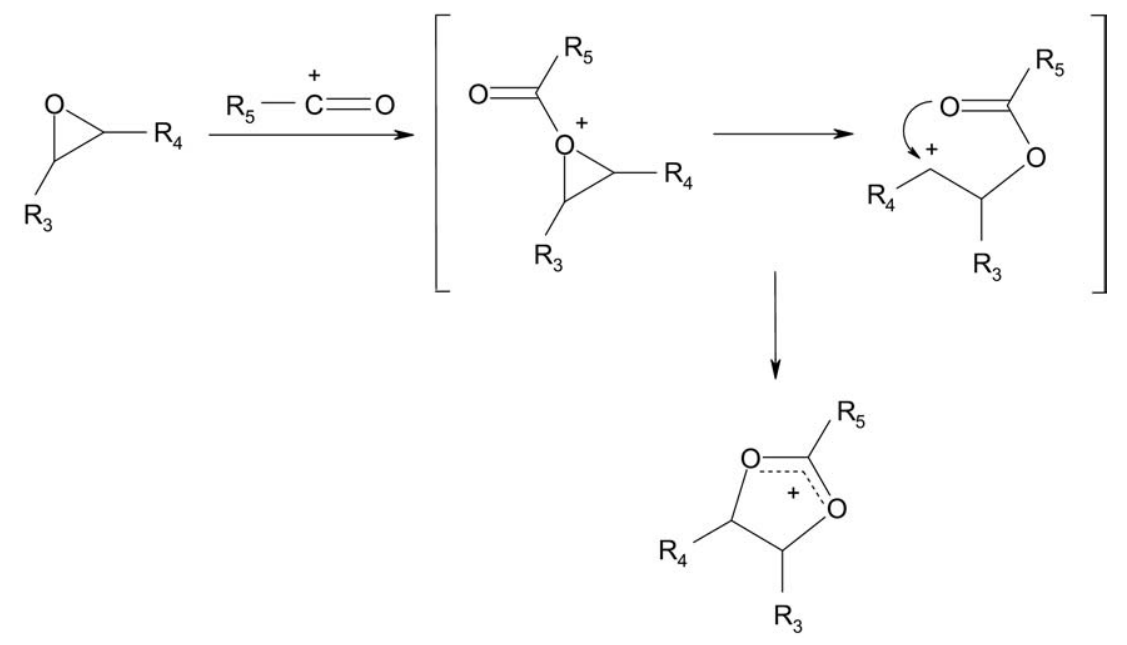

Scheme 2. Gas-phase Meerwein reaction of epoxides with acylium ions. 
Epoxide I: (R)-2-((5-bromo-2,3-difluorophenoxy)methyl)oxirane<smiles>Fc1cc(Br)cc(OCC2CO2)c1F</smiles>

\author{
$\mathrm{C}_{9} \mathrm{H}_{7} \mathrm{BrF}_{2} \mathrm{O}_{2}$ \\ Nominal mass $=264\left({ }^{79} \mathrm{Br}\right) / 266\left({ }^{81} \mathrm{Br}\right)$
}

Epoxide II: (2R,2'R)-2,2'-(5-bromo-2-fluoro-1,3-phenylene)bis(oxy)bis(methylene)dioxirane

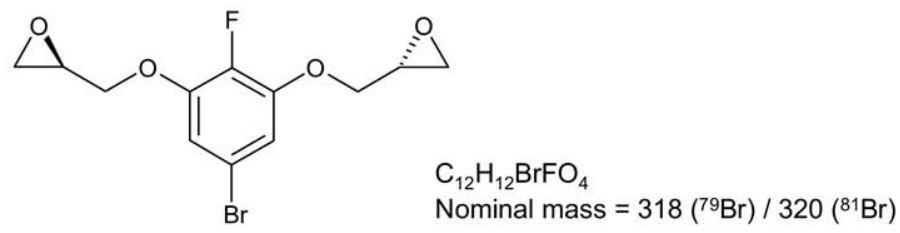

Epoxide III: (R)-2-(chloromethyl)oxirane

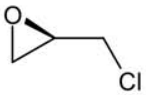

$\mathrm{C}_{3} \mathrm{H}_{5} \mathrm{ClO}$

Nominal mass $=92\left({ }^{35} \mathrm{Cl}\right) / 94\left({ }^{37} \mathrm{Cl}\right)$

Epoxide IV: 2-((S)-1-((R)-oxiran-2-yl)allyl)isoindoline-1,3-dione

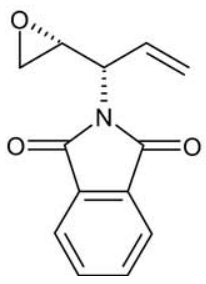

$\mathrm{C}_{13} \mathrm{H}_{11} \mathrm{NO}_{3}$

Nominal mass $=229$

Figure 1. Structures of the four epoxides used in the study.

sodium formate solution at $0.01 \mathrm{mg} / \mathrm{mL}$. All masses were corrected by the internal reference ion of $\mathrm{m} / \mathrm{z}$ 556.2771 (protonated Leu-Enk) that was introduced via the Lockspray source.

\section{Data-Dependent $M S^{2}, M S^{3}$, and $M S^{4}$ Experiments} on a Linear Ion Trap Mass Spectrometer

The data-dependent $\mathrm{MS}^{2}, \mathrm{MS}^{3}$, and $\mathrm{MS}^{4}$ experiments were performed on a Thermo Electron linear ion trap LTQ mass spectrometer controlled by Xcalibur 1.4 software (San Jose, CA, USA). The ESI source was operated in the positive ion mode under the following conditions: spray voltage, $-4.0 \mathrm{kV}$; heated capillary temperature, $300{ }^{\circ} \mathrm{C}$; capillary voltage, $30 \mathrm{~V}$; tube lens offset voltage, $30 \mathrm{~V}$; nitrogen sheath gas flow rate, 30 arbitrary units. In the full-scan $\mathrm{MS}^{2}, \mathrm{MS}^{3}$, and $\mathrm{MS}^{4}$ modes, the precursor ion of interest was isolated by applying multiple frequency waveforms to remove undesired ions through broadband excitation. The isolated ions were then subjected to a supplementary alternating current (AC) potential for resonant excitation to cause CID. The Mathieu $\mathrm{q}_{\mathrm{z}}$ values chosen for the resonance excitation and ejection were 0.25 and 0.88 , respectively. The activation time used was $30 \mathrm{~ms}$ with helium as the collision gas. The normalized activation energy was set to $25 \%$ of $0-5 \mathrm{~V}$ peak-to-peak potential.

\section{Single Ion Monitoring (SIM) and Multiple Reaction Monitoring (MRM) on a Triple Quadrupole Mass Spectrometer}

For the quantitative analysis, the SIM and MRM experiments were performed on an Agilent 6410 triple quadrupole mass spectrometer equipped with an Agilent 1200 HPLC system, which was controlled by MassHunter Workstation software (Agilent Technologies, Santa Clara, CA, USA). The ESI source was operated in the positive ion mode under the following conditions: spray voltage, $-4.0 \mathrm{kV}$; nitrogen drying gas flow rate and temperature, $12 \mathrm{~L} / \mathrm{min}$ and $300{ }^{\circ} \mathrm{C}$, respectively; nitrogen nebulizer gas pressure, 45 psi; dwell time, 880 ms; CID collision gas, nitrogen; collision energy for MRM, $15 \mathrm{eV}$. 


\section{Theoretical Calculations}

Theoretical calculations were performed based on density functional theory (DFT) using Becke's three-parameter hybrid functional with the Lee,Yang, and Parr correlation (B3LYP) and the 6-311+G(d,p) basis set [29]. Harmonic vibrational frequencies were calculated to characterize the stationary points and to obtain the zeropoint vibrational energies (ZPVEs), which were scaled by a factor of 0.96 and incorporated in the final proton affinity (PA) calculations [30]. The Gaussian 2003 program (rev. D.02) was used for all calculations [31].

\section{Results and Discussion}

\section{Atmospheric Pressure Gas-Phase Meerwein Reaction of Epoxides with Ethylnitrilium Ion}

Acetonitrile, one of the most commonly used organic mobile phases in the LC-MS analysis, can form ethylnitrilium ion via protonation under typical ESI, APCI, and APPI conditions. Ethylnitrilium ion $\left(\mathrm{CH}_{3}-\mathrm{C} \equiv \stackrel{+}{\mathrm{N}} \mathrm{H}\right.$ and its canonical form $\mathrm{CH}_{3}-\stackrel{+}{\mathrm{C}}=$ $\mathrm{NH})$ resembles acylium ions that have been known to efficiently undergo the gas-phase Meerwein reaction with epoxides in the gas phase [21,22]. The formation of the Meerwein reaction products of epoxides I-IV with ethylnitrilium ion were confirmed by the exact mass measurements within an error of $3.6 \mathrm{ppm}$. An appropriate atmospheric pressure environment facilitates efficient low-energy ion/molecule reactions in that a reactant ion and its products can be stabilized due to collisional cooling by the surrounding neutral molecules such as nitrogen gas in the API sources. As displayed in Figure 2, three epoxides (I, II, and III) selected in this study exhibit the favorable Meerwein reaction with ethylnitrilium ion under the ESI condition, probably as the result of collisional cooling of the reactant ion and the Meerwein products. Similarly, the Meerwein reaction occurs for all these three epoxides under the APCI and APPI conditions (spectra not shown). Of the two epoxide moieties in II, only one was observed to efficiently undergo the Meerwein reaction since it is unlikely for the associated Meerwein reaction product to proceed a further Meerwein reaction with ethylnitrilium ion via the cation ion/cation ion reaction. In the $\mathrm{H} / \mathrm{D}$ exchange experiment using $\mathrm{D}_{2} \mathrm{O}$ instead of

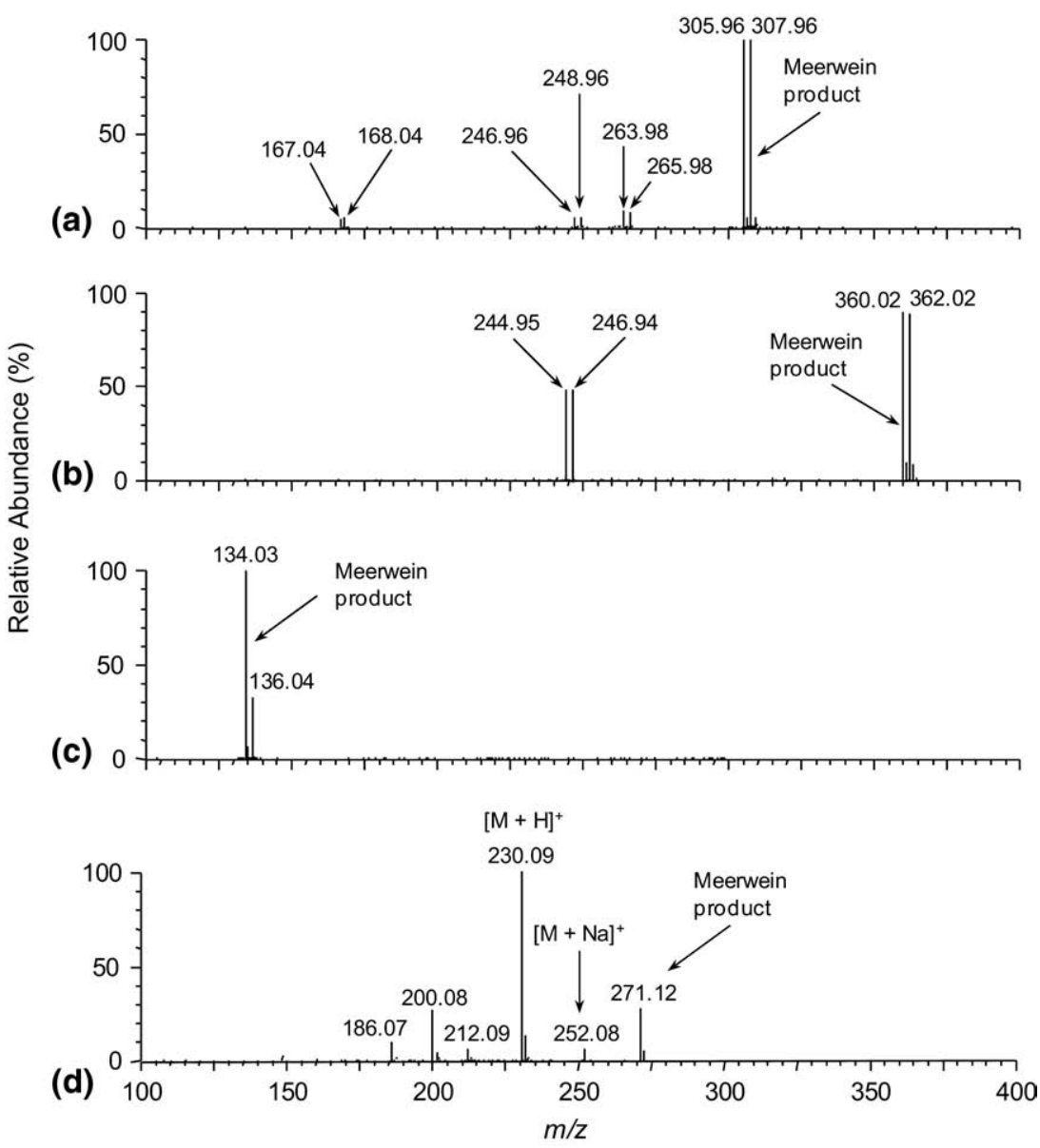

Figure 2. ESI-MS spectra of epoxides (a) I, (b) II, (c) III, and (d) IV that undergo the atmospheric pressure gas-phase Meerwein reaction with ethylnitrilium ion. 
$\mathrm{H}_{2} \mathrm{O}$ as the mobile phase, the protonated molecule of acetonitrile becomes the deuteronated species. Since epoxides I, II, and III have no exchangeable proton in their structures, their Meerwein reaction products are expected to exhibit an increase of 1 Da mass unit after H/D. This was confirmed by the experimental results supporting the cyclic structure of the gas-phase Meerwein reaction products [23].

There are some in-source fragmentation ions in the MS spectra of epoxides I and II (Figure 2a and b). For example, epoxide I exhibits the in-source fragmentation ions of $m / z 264\left({ }^{79} \mathrm{Br}\right)$ and $266\left({ }^{81} \mathrm{Br}\right)$ as the result of the characteristic net oxygen-by-nitrogen replacement in the molecule (Scheme 3). These ions exhibit the further loss of a molecule of $\mathrm{NH}_{3}$ to yield the ions of $\mathrm{m} / \mathrm{z} 247$ $\left({ }^{79} \mathrm{Br}\right)$ and $249\left({ }^{81} \mathrm{Br}\right)$. Epoxide II, on the other hand, does not give rise to such an oxygen-by-nitrogen replacement in the ESI source; instead, it undergoes a simple cleavage of the $\mathrm{C}-\mathrm{O}$ bond at the side chain affording the in-source fragmentation ions of $m / z 245\left({ }^{79} \mathrm{Br}\right)$ and 247 $\left({ }^{81} \mathrm{Br}\right)$. As for epoxide III (Figure $2 \mathrm{c}$ ), no in-source fragment ion was observable since it is a relatively small molecule. Epoxide IV mainly yields the proton transfer product along with a significant amount of the gasphase Meerwein reaction product in addition to some in-source fragment ions (Figure 2d). This is probably due to that the structurally unspecific proton-transfer reaction competes with the structurally specific Meerwein reaction based on the calculated PAs as discussed below.

The calculated PAs of epoxides I-IV and $\mathrm{CH}_{3} \mathrm{CN}$ are listed in Table 1. Using DFT at the B3LYP/6$311+\mathrm{G}(\mathrm{d}, \mathrm{p})$ level, the calculated PA for $\mathrm{CH}_{3} \mathrm{CN}$ as $188.06 \mathrm{kcal} / \mathrm{mol}$ shows an excellent agreement with the experimentally measured data of $188.2 \mathrm{kcal} / \mathrm{mol}$ using the kinetic method [32]. This verifies that the chosen

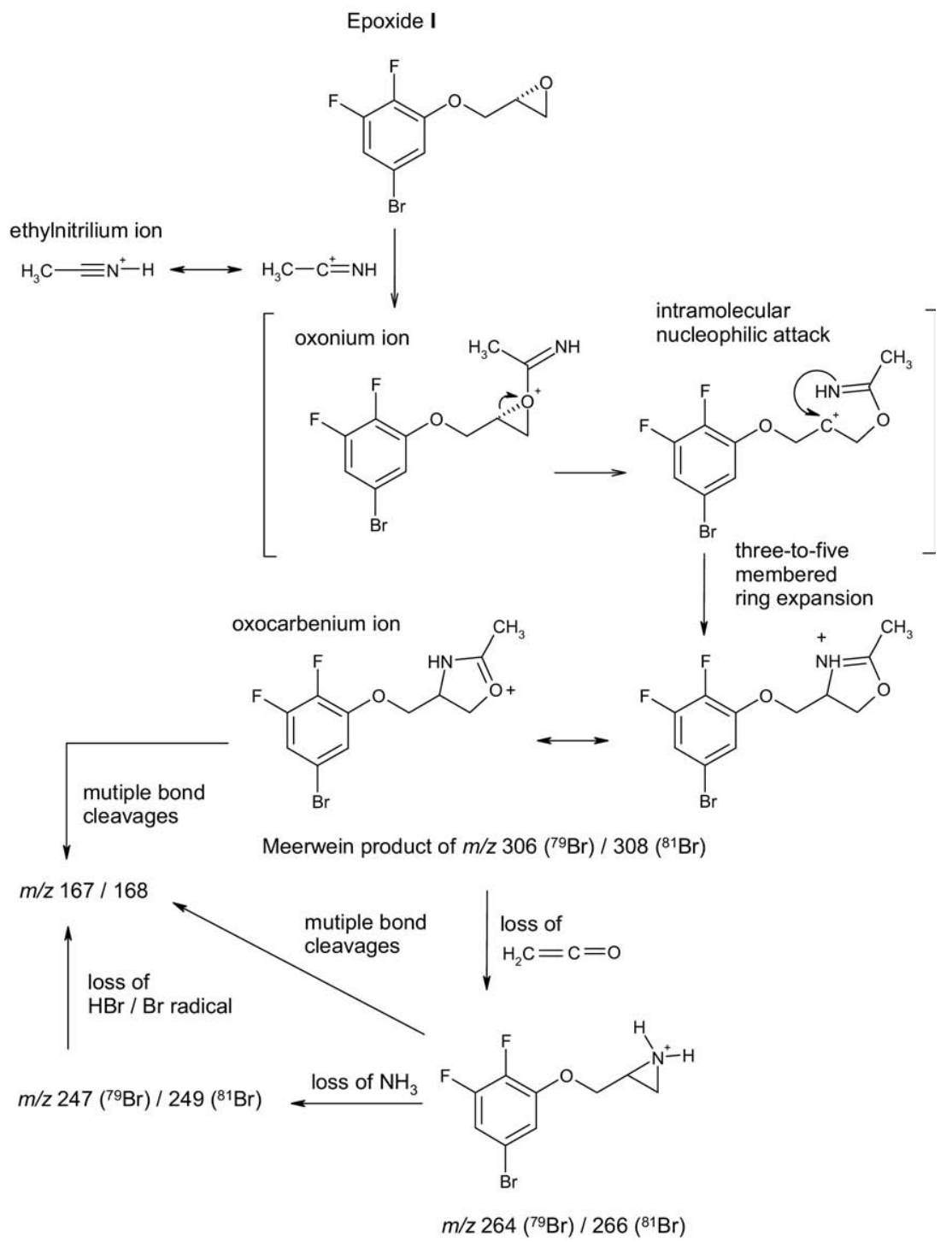

Scheme 3. Gas-phase Meerwein reaction of epoxide I with ethylnitrilium ion and its major fragmentation pathways. 
Table 1. The calculated proton affinities (PAs) of epoxides I-IV and $\mathrm{CH}_{3} \mathrm{CN}$

\begin{tabular}{lccc}
\hline Compound & $\begin{array}{c}\Delta \mathrm{H} \\
(\mathrm{kcal} / \mathrm{mol})^{\mathrm{a}}\end{array}$ & $\begin{array}{c}\Delta \text { ZPVE } \\
(\mathrm{kcal} / \mathrm{mol})^{\mathrm{b}}\end{array}$ & $\begin{array}{c}\mathrm{PA} \\
(\mathrm{kcal} / \mathrm{mol})^{\mathrm{c}}\end{array}$ \\
\hline \hline Epoxide I & -187.31 & 7.41 & 180.20 \\
Epoxide II & -176.82 & 7.34 & 169.78 \\
Epoxide III & -190.39 & 7.67 & 183.02 \\
Epoxide IV & -219.24 & 7.84 & 211.71 \\
$\mathrm{CH}_{3} \mathrm{CN}$ & -194.42 & 6.63 & $188.06^{\mathrm{d}}$ \\
\hline
\end{tabular}

${ }^{a} \Delta \mathrm{H}$ is the enthalpy change for the protonation reaction $\mathrm{M}(\mathrm{g})+\mathrm{H}^{+}(\mathrm{g})=$ $\mathrm{MH}^{+}(\mathrm{g})$ by taking the enthalpy of a proton as $1.482 \mathrm{kcal} / \mathrm{mol}$ into account.

${ }^{\mathrm{b}} \triangle \mathrm{ZPVE}$ is the difference of zero-point vibrational energies for the above protonation reaction.

${ }^{\mathrm{CPA}}=-(\Delta \mathrm{H})-\Delta \mathrm{ZPVE} \times 0.96$.

${ }^{\mathrm{d}}$ The measured PA of $\mathrm{CH}_{3} \mathrm{CN}$ by the kinetic method is $188.2 \mathrm{kcal} / \mathrm{mol}$ (see reference [32]), which shows an excellent agreement with the calculated PA.

level of theory is appropriate for the calculations of PAs of epoxides I-IV. Acetonitrile, which is the solvent to generate ethylnitrilium ion by protonation, appears to have higher PA than those of epoxides I-III (Table 1). This indicates that the proton transfer reaction is not favored for these compounds. As expected, the structurally unspecific reaction giving rise to the proton transfer or hydride abstraction product was not observed. In contrast, epoxide IV that contains a tertiary amine is expected and confirmed by the theoretical calculation to have higher PA than acetonitrile. Thus it mainly undergoes the proton transfer reaction rather than the gas-phase Meerwein reaction. This is supported by the experimental data (Figure 2d). In summary, a favorable gas-phase Meerwein reaction of epoxides is expected if the epoxide of interest has a lower PA than acetonitrile.

For comparison, ionization and ion/molecule reactions of epoxides I-IV were examined in methanol (instead of acetonitrile), another commonly used organic mobile phase in the LC-MS analysis. The results are summarized in Table 2. As expected, the gas-phase Meerwein reaction does not occur due to lacking the source of ethylnitrilium ion in absence of acetonitrile. Epoxides I, II, and IV afford protonated molecules and/or sodiated species under the ESI, APCI, and APPI conditions, while epoxide III fails to ionize by either protonation or sodiation. Epoxides I and II exhibit more favorable formation of the sodiated species rather than the protonated molecules, probably due to their low PAs but high sodium affinities and strong cation- $\pi$ interaction between the phenyl ring and sodium cation $[33,34]$. When a compound has a high PA, protonation will compete with sodiation and this is the case for epoxide IV, which affords the intense protonated molecule in addition to the sodiated species. However, detailed discussion about the favorable formation of sodiated species of epoxides during APCI and APPI when using the $\mathrm{CH}_{3} \mathrm{OH}$ mobile phase is beyond the scope of this study.

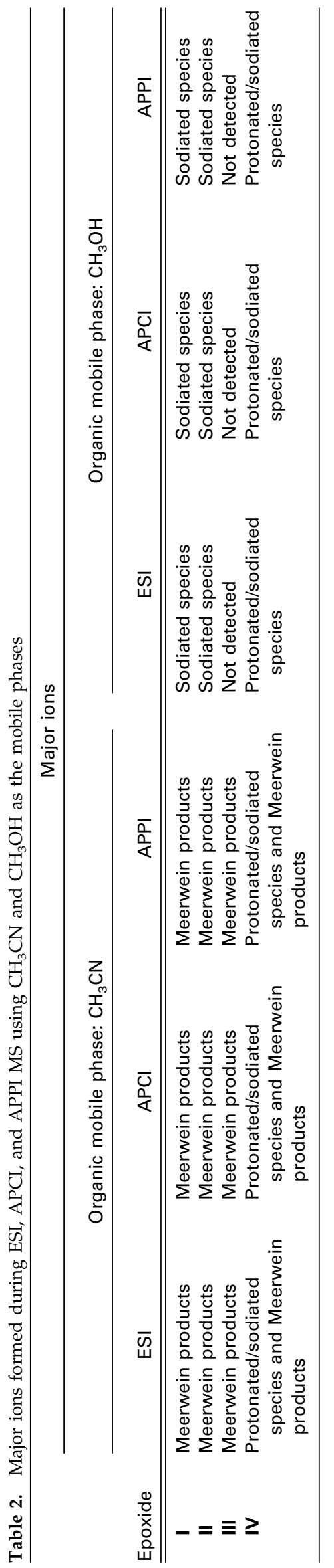




\section{CID of the Meerwein Reaction Products}

The gas-phase Meerwein reaction products resulting from the reaction of epoxides with ethylnitrilium ion were mass-selected and subjected to CID. To obtain unambiguous structural assignments for epoxides I-III, the precursor ions corresponding to the contributions from the mono isotopes of ${ }^{79} \mathrm{Br}$ and ${ }^{81} \mathrm{Br}$ or ${ }^{35} \mathrm{Cl}$ and ${ }^{37} \mathrm{Cl}$ before and after the H/D exchange were individually selected for the CID experiments. For epoxide I, the MS/MS spectra were obtained for the precursor ions of $\mathrm{m} / \mathrm{z} 306\left({ }^{79} \mathrm{Br}\right) / 308\left({ }^{81} \mathrm{Br}\right.$ ) (Figure $3 \mathrm{a}$ and b) and $\mathrm{m} / \mathrm{z} 307$ $\left({ }^{79} \mathrm{Br}\right) / 309\left({ }^{81} \mathrm{Br}\right)$ (Figure 3c and d), which correspond to the protonated and deuteronated molecules, respectively. These $\mathrm{MS}^{2}$ data show one fragmentation pathway via the elimination of ethenone that leads to the net oxygen-by-nitrogen replacement within the molecule of epoxide I. This replacement results in a characteristic mass shift of $1 \mathrm{Da}$ lower than the original epoxide, providing evidence for the cyclic nature of the gasphase Meerwein product; otherwise CID would reveal the loss of acetonitrile rather than ethenone. Furthermore, as depicted in Scheme 3, the possible pathways that yield the major fragment ions of $\mathrm{m} / \mathrm{z} 167 / 168$ are: (1) the Meerwein product of epoxide I undergoes the multiple bond cleavages and (2) the $\mathrm{MS}^{2}$ product ion of $\mathrm{m} / \mathrm{z} 264\left({ }^{79} \mathrm{Br}\right)$ or $266\left({ }^{81} \mathrm{Br}\right.$ ) (via the elimination of ethenone) undergoes further fragmentation via the losses of $\mathrm{NH}_{3}$ and $\mathrm{HBr} / \mathrm{Br}$ radical. To test this hypoth- esis, $\mathrm{MS}^{2}$ of $m / z 306\left({ }^{79} \mathrm{Br}\right)$ or $308\left({ }^{81} \mathrm{Br}\right)$ and $\mathrm{MS}^{3}$ of $\mathrm{m} / \mathrm{z}$ $264\left({ }^{79} \mathrm{Br}\right)(306 \rightarrow 264)$ or $266\left({ }^{81} \mathrm{Br}\right)(308 \rightarrow 266)$ as well as $\mathrm{MS}^{4}$ of $m / z 247\left({ }^{79} \mathrm{Br}\right)(306 \rightarrow 264 \rightarrow 247)$ or $m / z 249$ $\left({ }^{81} \mathrm{Br}\right)(308 \rightarrow 266 \rightarrow 249)$ were performed on the linear ion trap mass spectrometer under the resonant excitation (to avoid further fragmentation). It was found that the $\mathrm{MS}^{2}, \mathrm{MS}^{3}$, and $\mathrm{MS}^{4}$ experiments can afford the fragment ions of $m / z 167 / 168$, supporting the proposed fragmentation pathways occurring in the Q-TOF mass spectrometer as described in Scheme 3. It is worth noting that such fragmentation pathways were also observed to occur in the API sources, although the level of fragmentation was much less. As for epoxide III, fragmentation of its Meerwein reaction product predominantly undergoes the elimination of ethenone followed by a further loss of $\mathrm{NH}_{3}$ (Figure $4 \mathrm{a}$ and $\mathrm{b}$ ).

Increased structural complexity with the presence of other functional groups or substituents (when placed at positions that favor specific bond cleavages) induces other competitive dissociations. This is exemplified by the fragmentation of the Meerwein product of epoxide II (Figure 4c and d) with a more complex MS/MS spectrum consisting of a set of structurally characteristic fragment ions. Similar to epoxides I and III, the elimination of ethenone was observed to give rise to the characteristic product ion of $\mathrm{m} / \mathrm{z} 318\left({ }^{79} \mathrm{Br}\right)$ or $320\left({ }^{81} \mathrm{Br}\right)$ that undergoes a further loss of $\mathrm{NH}_{3}$ to yield the product ion of $m / z 301\left({ }^{79} \mathrm{Br}\right)$ or $303\left({ }^{81} \mathrm{Br}\right)$. There is a

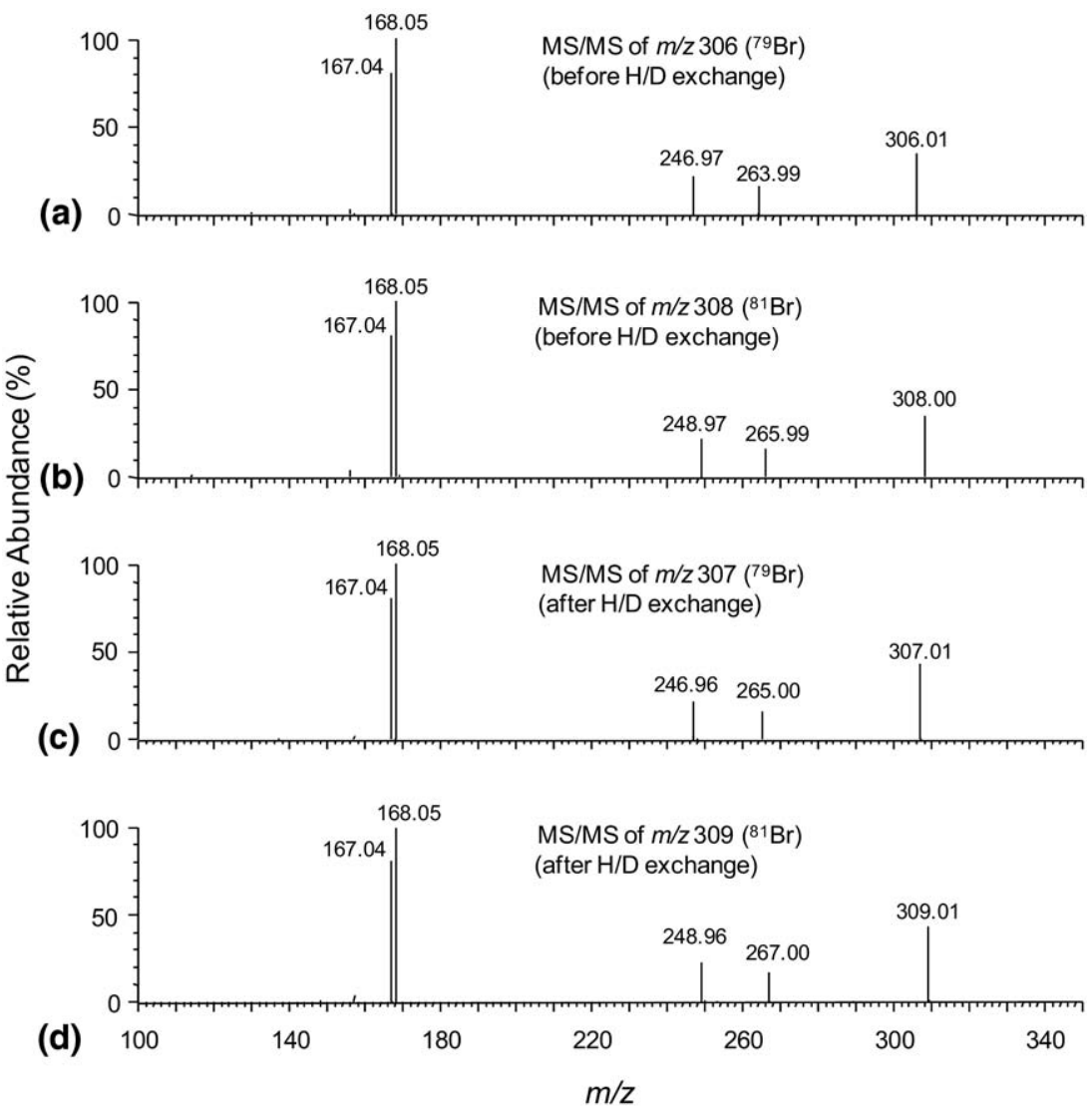

Figure 3. MS/MS spectra of the Meerwein reaction product of epoxide $\mathbf{I}$ of $(\mathbf{a}) \mathrm{m} / z 306\left({ }^{79} \mathrm{Br}\right)$ in $\mathrm{H}_{2} \mathrm{O}$, (b) $m / z 308\left({ }^{81} \mathrm{Br}\right)$ in $\mathrm{H}_{2} \mathrm{O}$, (c) $\mathrm{m} / \mathrm{z} 307\left({ }^{79} \mathrm{Br}\right)$ in $\mathrm{D}_{2} \mathrm{O}$, and (d) $\mathrm{m} / \mathrm{z} 309\left({ }^{81} \mathrm{Br}\right)$ in $\mathrm{D}_{2} \mathrm{O}$. 


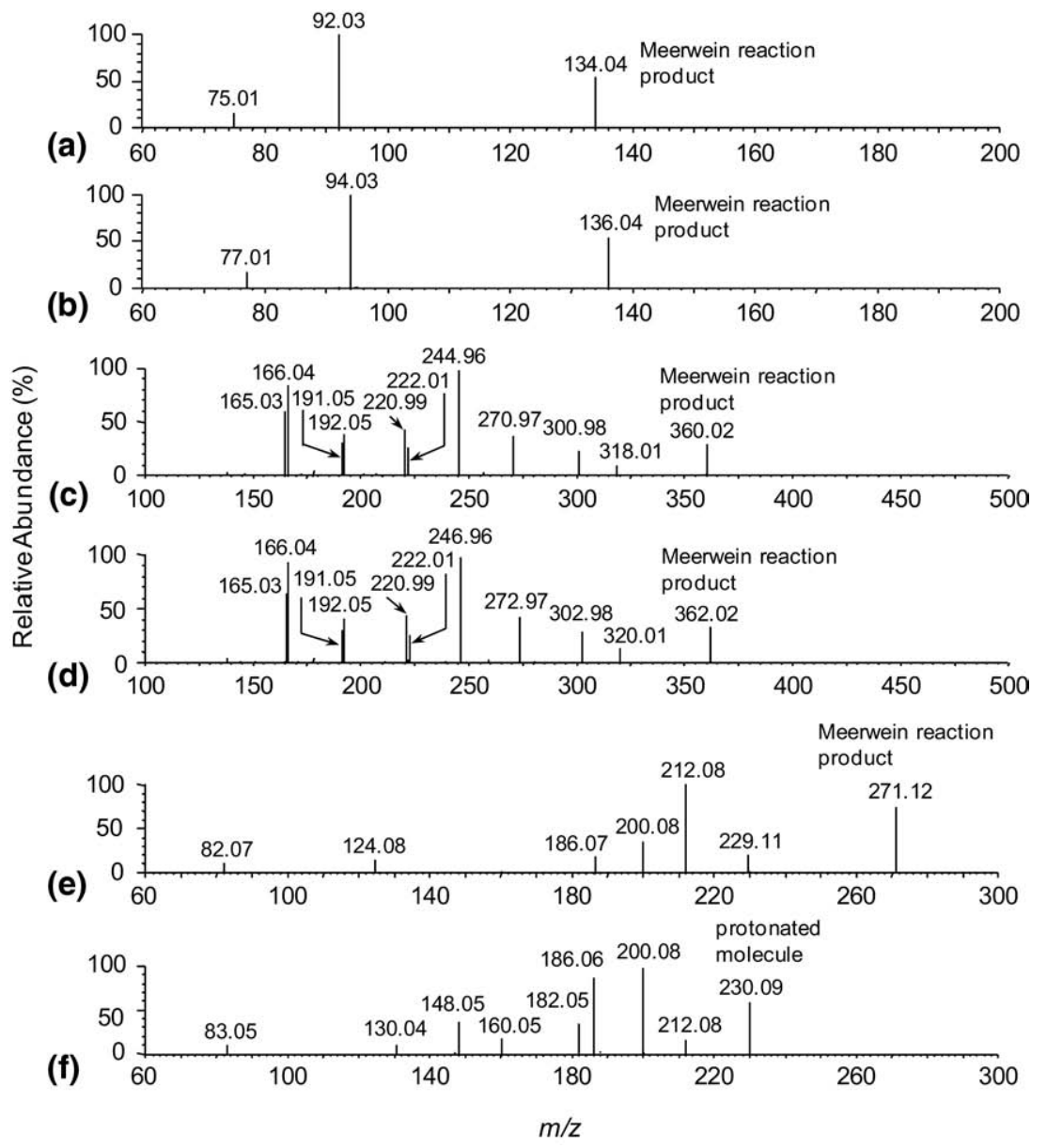

Figure 4. MS/MS spectra of the Meerwein reaction products of epoxide III of (a) $\mathrm{m} / z 134\left({ }^{35} \mathrm{Cl}\right)$ and (b) $\mathrm{m} / \mathrm{z} 136\left({ }^{37} \mathrm{Cl}\right)$, epoxide II of (c) $\mathrm{m} / \mathrm{z} 360\left({ }^{79} \mathrm{Br}\right)$ and (d) $\mathrm{m} / \mathrm{z} 362\left({ }^{81} \mathrm{Br}\right)$, and epoxide IV of (e) $\mathrm{m} / \mathrm{z} 271$ as well as the protonated molecule of epoxide IV of (f) $\mathrm{m} / \mathrm{z} 230$.

fragmentation pathway possibly via the $\mathrm{C}-\mathrm{O}$ bond cleavage of the side chain generating the major fragment ion of $\mathrm{m} / \mathrm{z} 245\left({ }^{79} \mathrm{Br}\right)$ or $247\left({ }^{81} \mathrm{Br}\right.$ ) (Scheme 4). In addition, the further fragmentation via the sequential losses of $\mathrm{HBr}$ and $\mathrm{Br}$ radical were observed for the fragment ions of $\mathrm{m} / \mathrm{z} 301\left({ }^{79} \mathrm{Br}\right)$ or $303\left({ }^{81} \mathrm{Br}\right), \mathrm{m} / \mathrm{z} 271$ $\left({ }^{79} \mathrm{Br}\right)$ or $273\left({ }^{81} \mathrm{Br}\right)$, and $\mathrm{m} / \mathrm{z} 245\left({ }^{79} \mathrm{Br}\right)$ or $247\left({ }^{81} \mathrm{Br}\right)$ to yield the ion pairs of $m / z 221 / 222,191 / 192$, and $165 /$ 166, respectively.

Epoxide IV can form both the gas-phase Meerwein reaction product $(\mathrm{m} / \mathrm{z} 271)$ and the protonated molecule $(\mathrm{m} / \mathrm{z} 230)$. Both of which were subject to CID and the $\mathrm{MS}^{2}$ spectra are displayed in Figure 4e and f, respectively. Akin to epoxides I-III, CID of the Meerwein reaction product of epoxide IV $(\mathrm{m} / \mathrm{z} 271)$ gives rise to the product ion of $\mathrm{m} / \mathrm{z} 229$ via the elimination of ethenone. As shown in Scheme 5, the other fragmentation pathways corresponding to $\mathrm{m} / \mathrm{z} 271$ (e.g., giving the fragment ion of $\mathrm{m} / \mathrm{z} 124$ ) and $\mathrm{m} / \mathrm{z} 230$ (e.g., yielding the fragment ions of $m / z 182,160,148$, and 130) appear to be quite different. This is probably due to the charge-remote fragmentation that occurs to the
Meerwein reaction product with the fixed charge versus the mobile proton (charge) in the protonated molecule [35].

\section{Energetics of the Gas-Phase Meerwein Reaction}

Taking epoxide I as an example, the energetics of the gas-phase Meerwein reaction with ethylnitrilium ion was calculated and the potential energy surface diagram is depicted in Figure 5. Similar to acylium and thioacylium ions [21], the Meerwein reaction with ethylnitrilium ion is highly exothermic (by $-75.76 \mathrm{kcal} /$ mol) and hence the reaction is thermodynamically favorable. This is possibly owing to the more stable five-membered ring of the Meerwein reaction product than the three-membered ring of epoxide I (reactant). The calculated energies (relative to the energy of the reactant) of intermediates $\mathbf{A}$ and $\mathbf{B}$ are -12.96 and 10.84 $\mathrm{kcal} / \mathrm{mol}$, respectively. This indicates that the energy required for the occurrence of the Meerwein reaction is relatively small. In contrast, the dissociation of the Meerwein reaction product needs to overcome 58.04 


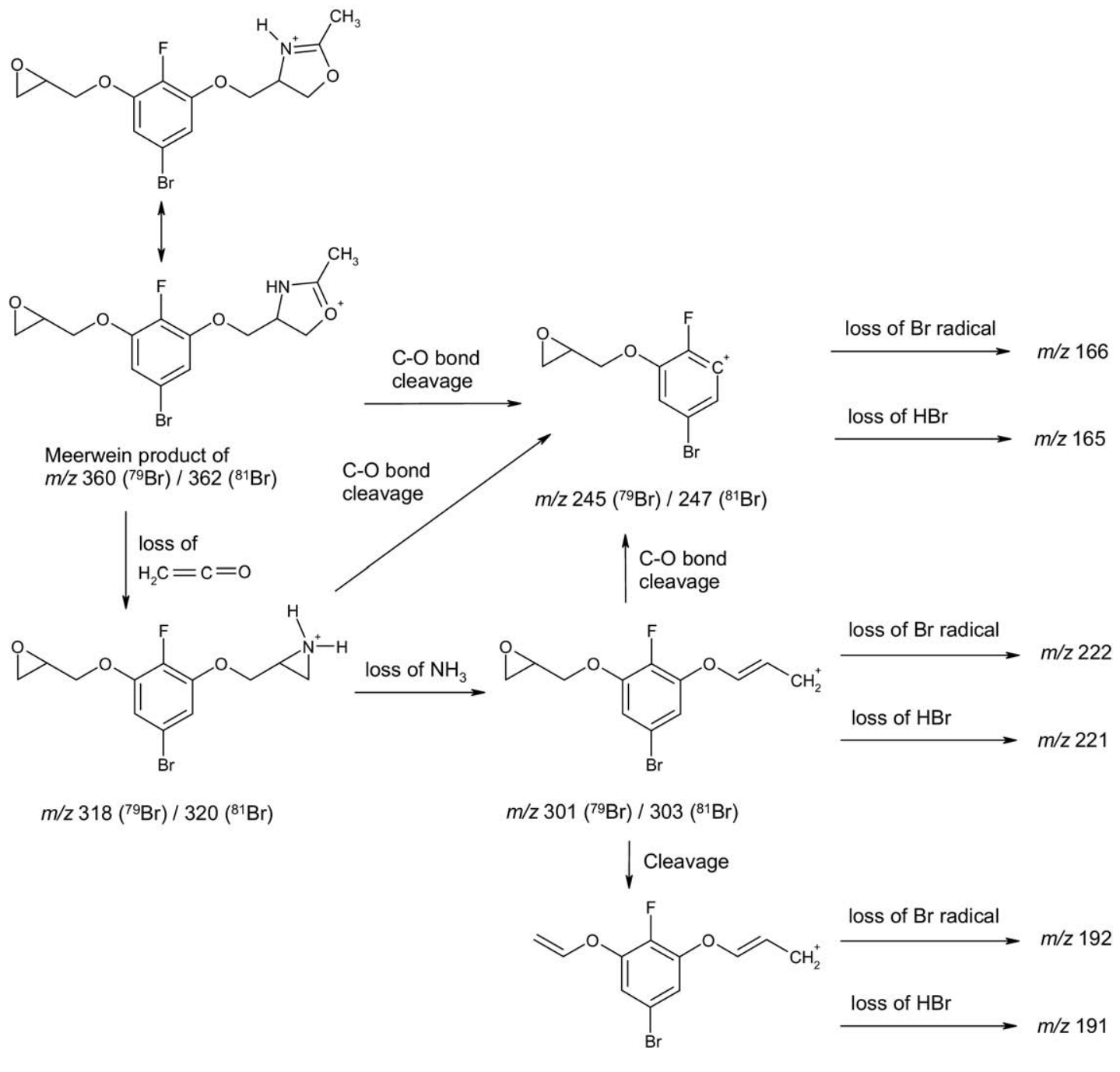

$\mathrm{m} / \mathrm{z} 271\left({ }^{79} \mathrm{Br}\right) / 273\left({ }^{81} \mathrm{Br}\right)$

Scheme 4. Major fragmentation pathways of the gas-phase Meerwein reaction product of epoxide II with ethylnitrilium ion.

$\mathrm{kcal} / \mathrm{mol}$ energy barrier to give rise to the net oxygenby-nitrogen replacement product of $\mathrm{m} / \mathrm{z} 264\left({ }^{79} \mathrm{Br}\right)$ or $266\left({ }^{81} \mathrm{Br}\right)$ along with ethenone. The theoretical calculations also suggest that the gas-phase route to convert epoxides into their nitrogen analogs via the elimination of ethenone upon CID is a more thermodynamically favorable process (by $-17.72 \mathrm{kcal} / \mathrm{mol}$ ) than reverting to the original epoxide $\mathbf{I}$. The calculated energetics for promoting the net oxygen-by-nitrogen replacement is in agreement with the reported value $(-16.8 \mathrm{kcal} / \mathrm{mol})$ for leading to the net oxygen-by-sulfur replacement [21].

\section{Potential Applications in Quantitative Analysis of Epoxides Using the Gas-Phase Meerwein Reaction}

Although a number of GC-MS and LC-UV-MS methods have been developed for analysis of genotoxic epoxides, obtaining a highly sensitive and selective method for quantitation of such class of GTIs at trace levels (ppm) in drug substances and products is still an ongoing challenge [36]. Recently, a chemical derivatization approach was reported where epoxides can be converted into tertiary amines by reacting with dimethylamine (DMA) as the derivatization agent [37]. The advantage of the method is that it not only introduces an ionizable site into the analyte for protonation but also stabilizes certain epoxides if unstable. Chemical derivatization has been used successfully to quantify several epoxides in various active pharmaceutical ingredients. The gasphase Meerwein reaction of epoxides with ethylnitrilium ion generated in the API-MS sources, on the other hand, offers an alternative approach enabling direct and selective analysis of epoxides. It takes advantage of the use of acetonitrile in the LC-MS mobile phase, thus eliminating the extra chemical derivatization step. The feasibility has been demonstrated herein using epoxide I as the model compound. A solution of epoxide I at a 

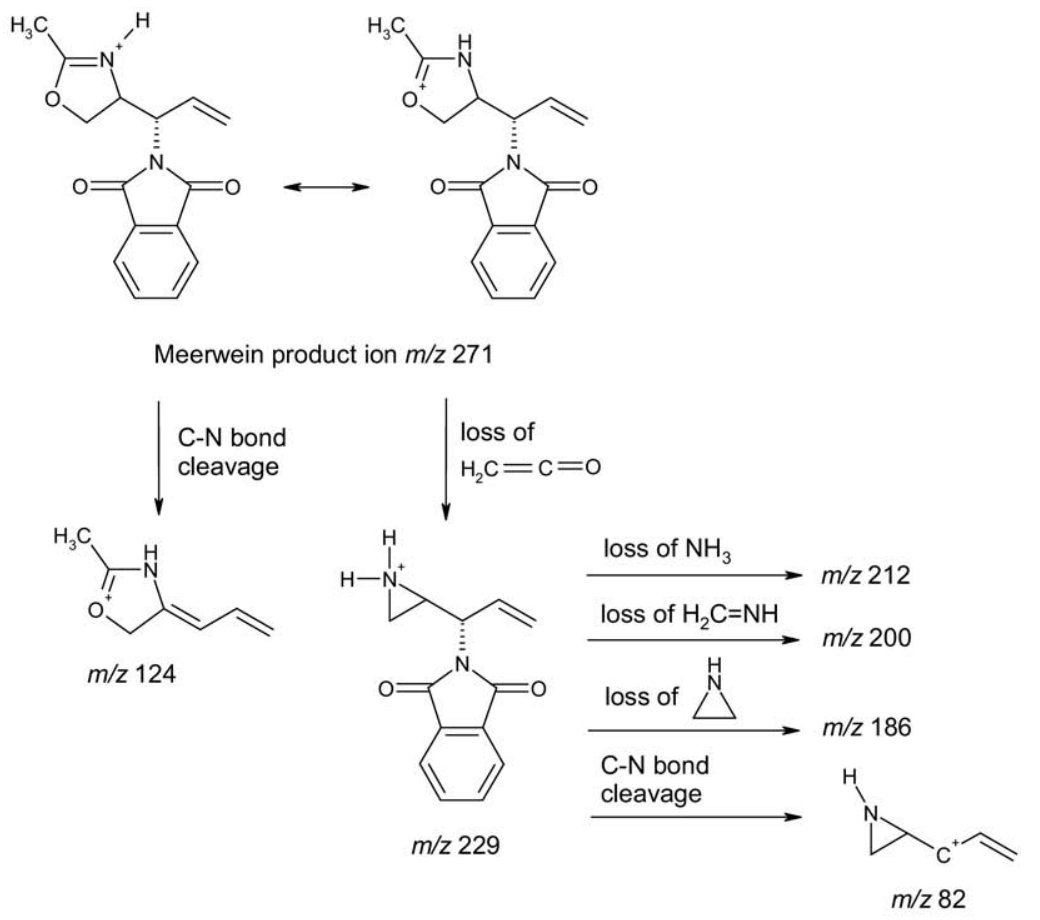

(a)
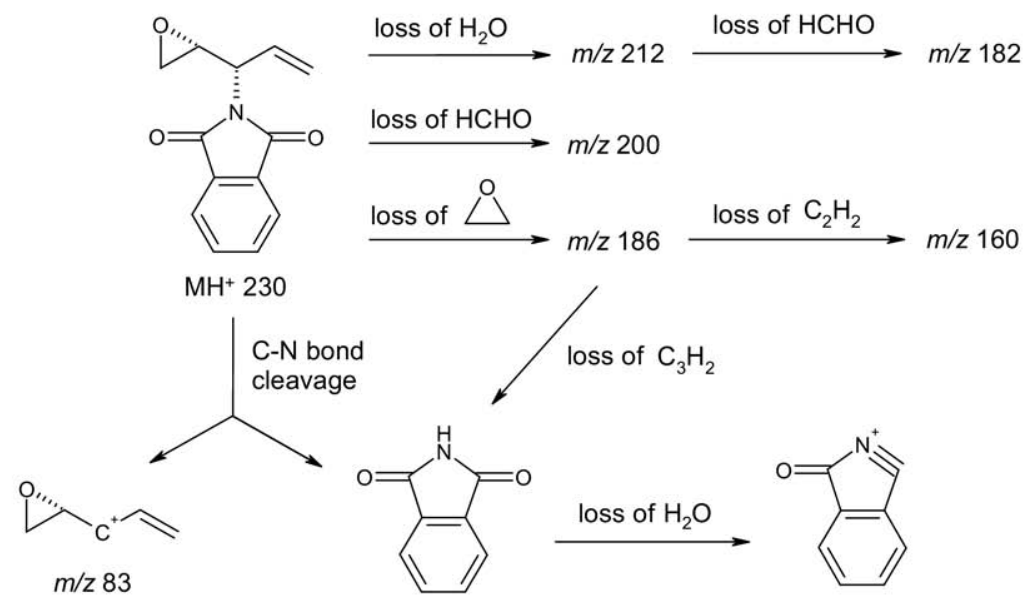

(b)

$\mathrm{MH}^{+} 148$

$m / z 130$

Scheme 5. Major fragmentation pathways of (a) the gas-phase Meerwein reaction product of epoxide IV with ethylnitrilium ion and (b) the protonated molecule of epoxide IV.

concentration level as low as $0.8 \mathrm{ng} / \mathrm{mL}$ was detected with a signal-to-noise ratio $(\mathrm{S} / \mathrm{N})$ of 21 (Figure 6). A linear calibration curve from 0.8 to $40 \mathrm{ng} / \mathrm{mL}$ was achieved $\left(R^{2}>0.994\right.$, data not shown) using the SIM detection method by monitoring the Meerwein reaction product of $\mathbf{I}\left[\mathrm{m} / \mathrm{z} 306\left({ }^{79} \mathrm{Br}\right)\right.$ or $\left.308\left({ }^{81} \mathrm{Br}\right)\right]$. Moreover, if the MRM detection is employed on a triple quadrupole instrument, one can take the advantage of the characteristic fragment pathways (e.g., that lead to the net oxygen-by-nitrogen replacement upon CID of the Meerwein reaction product) to enhance the detection selectivity. Similar sensitivity and linearity $\left(\mathrm{R}^{2}>0.996\right)$ by utilizing the MRM transition $\mathrm{m} / \mathrm{z} 306 \rightarrow 264\left({ }^{79} \mathrm{Br}\right)$ or $\mathrm{m} / \mathrm{z}$ $308 \rightarrow 266\left({ }^{81} \mathrm{Br}\right)$ were achieved (data not shown).

\section{Conclusions}

Epoxides are shown to efficiently undergo of the gasphase Meerwein reaction with ethylnitrilium ion generated during the LC-MS analysis under the typical conditions of ESI, APCI, and APPI, resulting in a gain of $42 \mathrm{Da}$ to the epoxides in the mass spectra. This should not be erroneously interpreted as a $\mathrm{CH}_{3} \mathrm{CN}$-adduct ion although it has the same $\mathrm{m} / \mathrm{z}$. This Meerwein reaction proceeds by the initial formation of an oxonium ion followed by rapid ring opening, and then ring closure that is promoted by an intramolecular nucleophilic attack. These steps result in three-to-five-membered ring expansion to yield the Meerwein reaction product. 


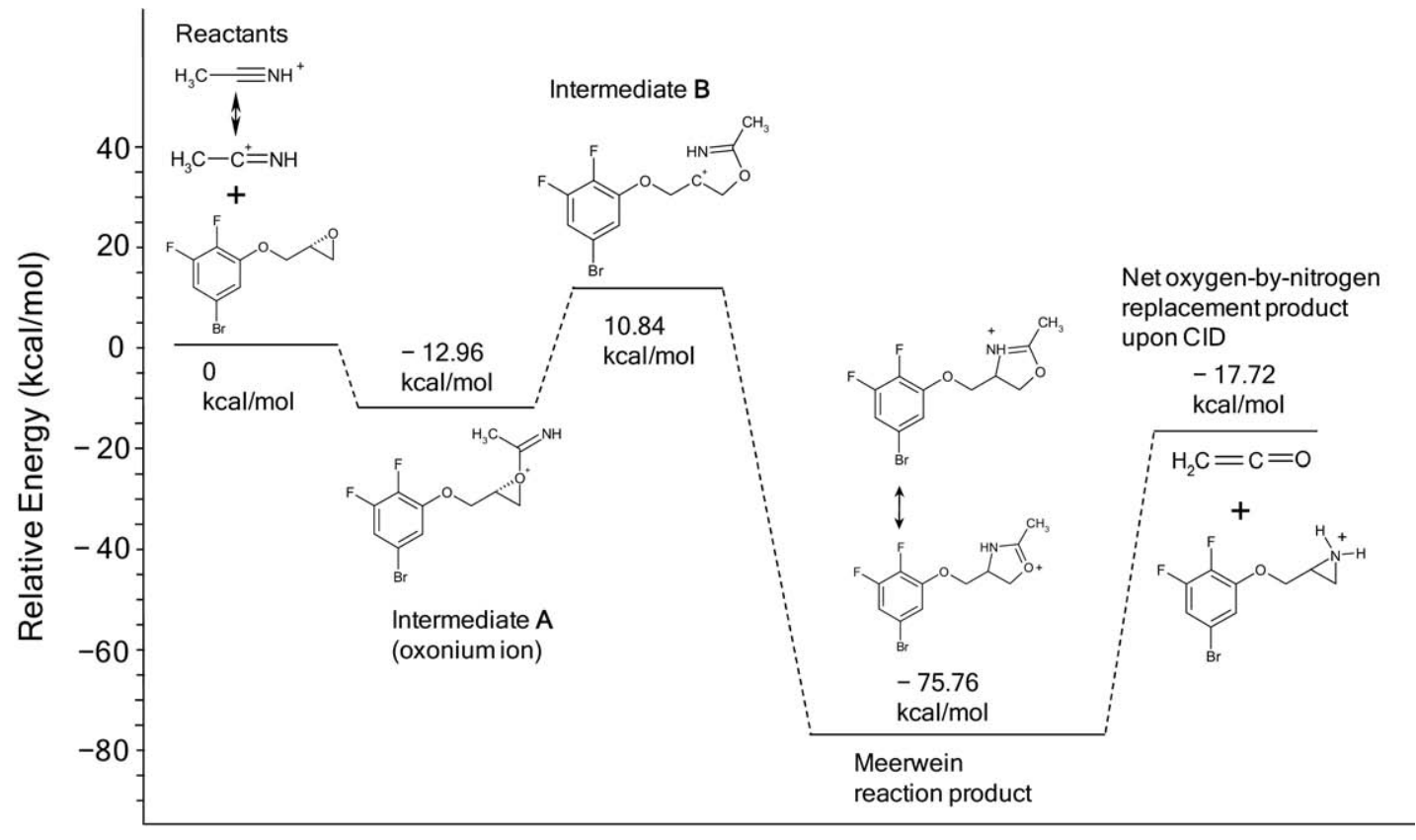

Meerwein Reaction Coordinate

Figure 5. The DFT calculated potential energy surface diagram for the gas-phase Meerwein reaction of epoxide I with ethylnitrilium ion followed by the elimination of ethenone upon CID.

The theoretical calculations show that the gas-phase Meerwein reaction is highly exothermic (e.g., by -75.6 $\mathrm{kcal} / \mathrm{mol}$ for epoxide I); therefore, it is thermodynamically favorable. When the reaction product is subjected to CID, ethenone is eliminated, constituting a gas-phase route to convert epoxides into their nitrogen analogs. This net oxygen-by-nitrogen replacement results in a characteristic mass shift of $1 \mathrm{Da}$, providing evidence for the cyclic nature of the gas-phase Meerwein products. Understanding of such a gas-phase ion/molecule reaction can help improve the sensitivity and selectivity for the detection of epoxides. The gas-phase Meerwein reaction of epoxides with ethylnitrilium ion not only

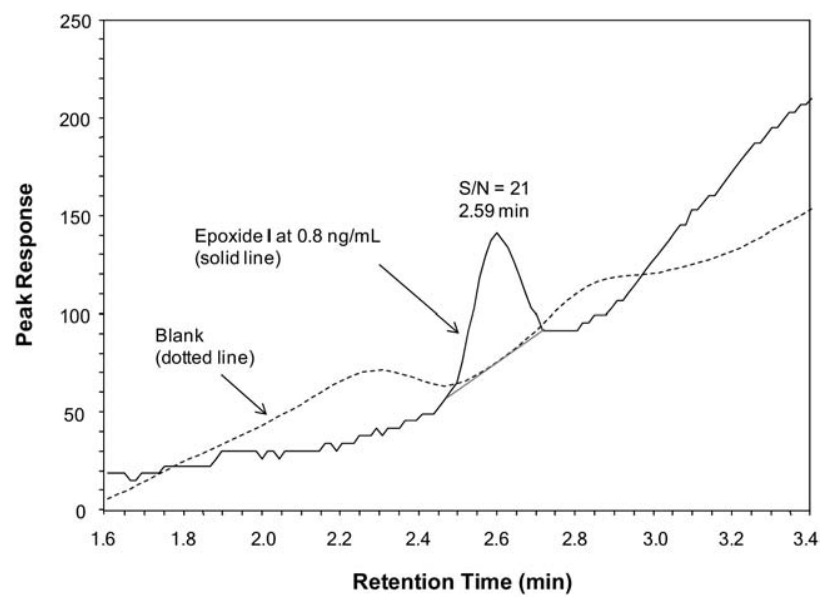

Figure 6. Overlay chromatograms of the standard of epoxide I at $0.8 \mathrm{ng} / \mathrm{mL}$ and the blank monitored by SIM at $\mathrm{m} / \mathrm{z} 306\left({ }^{79} \mathrm{Br}\right)$. provides a means for structural identification but also offers a novel and fast approach for the direct LC-MS analysis of epoxide pharmaceutical impurities that are of genotoxic concern. A real world application for the quantitation by SIM and MRM is yet to be demonstrated but the proof of concept with respect to detecting epoxide I at sub-ng/mL concentration has been achieved.

\section{Acknowledgments}

The authors acknowledge Dr. Sonya Kennedy-Gabb and Dr. Mark H. Kleinman of Analytical Sciences (GlaxoSmithKline) for the quantitation experiments and the critical review of the manuscript, respectively. The authors thank Dr. Steven N. Goodman and Ms. Qiaogong Su of Synthetic Chemistry (GlaxoSmithKline) for providing the samples in this study.

\section{References}

1. Cooks, R. G.; Chen, H.; Eberlin, M. N.; Zheng, X.; Tao, W. A. Polar Acetylization and Transacetalization in the Gas Phase: The Eberlin Reaction. Chem. Rev. 2006, 106, 188-211.

2. Kenttämaa, H. I.; Cooks, R. G. Identification of Protonated $\beta$-Hydroxycarbonyl Compounds by Reactive Collisions in Tandem Mass Spectrometry. J. Am. Chem. Soc. 1989, 111, 4122-4123.

3. Brodbelt, J. S. Analytical Applications of Ion-Molecule Reactions. Mass Spectrom. Rev. 1997, 16, 91-110.

4. Eberlin, M. N. Structurally Diagnostic Ion/Molecule Reactions: Class and Functional-Group Identification by Mass Spectrometry. J. Mass Spectrom. 2006, 41, 141-156.

5. Eberlin, M. N.; Cooks, R. G. Polar $\left[4+2^{+}\right]$Diels-Alder Cycloadditions of Acylium Ions in the Gas Phase. J. Am. Chem. Soc. 1993, 115, 9226-9233.

6. Eberlin, M. N. Gas-Phase Polar Cycloadditions. Int. J. Mass Spectrom. 2004, 235, 263-278.

7. Castle, L. W.; Gross, M. L. The Cycloaddition of the 1,3-Butadiene Radical Cation with Acrolein and Methyl Vinyl Ketone. Org. Mass Spectrom. 1989, 24, 637-646. 
8. Shen, J.; Evans, C.; Wade, N.; Cooks, R. G. Ion-Ion Collisions Leading to Formation of $\mathrm{C}-\mathrm{C}$ Bonds at Surfaces: An Interfacial Kolbe Reaction. J. Am. Chem. Soc. 1999, 121, 9762-9763.

9. Sheldon, J. C.; Bowie, J. H.; Dua, S.; Smith, J. D.; O'Hair, R. A. J. The Gas-Phase Cannizzaro Disproportionation Reactions of Benzaldehyde and Pivaldehyde. J. Org. Chem. 1997, 62, 3931-3937.

10. Hass, G. W.; Gross, M. L. Gas-Phase Base-Catalyzed Claisen-Schmidt Reactions of the Acetone Enolate Anion with Various Para-Substituted Benzaldehydes. J. Am. Soc. Mass Spectrom. 1996, 7, 82-92.

11. van der Waal, J. C.; Kunkeler, P. J.; Tan, K.; van Bekkum, H. A Selective Catalyst for the Gas-Phase Meerwein-Ponndorf-Verley, and Oppenauer Reactions. I. Catal. 1998, 173, 74-83.

12. Glish, G. L.; Cooks, R. G. The Fischer Indole Synthesis and Pinacol Rearrangement in the Mass Spectrometer. J. Am. Chem. Soc. 1978, 100, 6720-6725.

13. Adams, G. W.; Bowie, J. H.; Hayes, R. N. Does the Lossen Rearrangement Occur in the Gas Phase? J. Chem. Soc. Perkin. Trans. 2 Phys. Org. Chem. 1991, 5, 689-693.

14. Lebedev, A. T.; Hayes, R. N.; Bowie, J. H. Anionic Rearrangement in the Gas Phase. The Negative-Ion Wolff Rearrangement. J. Chem. Soc. Perkin. Trans. 2 Phys. Org. Chem. 1991, 8, 1127-1129.

15. Sabino, A. A.; Machado, A. H. L.; Correia, C. R. D.; Eberlin, M. N. Reactive Intermediates: Probing the Mechanism of the Heck Reaction with Arene Diazonium Salts by Electrospray Mass and Tandem Mass Spectrometry. Angew. Chem. Int. Ed. 2004, 43, 2514-2518.

16. O'Hair, R. A. J.; Vrkic, A. K.; James, P. F. Gas-Phase Synthesis and Reactivity of the Organomagnesates $\left[\mathrm{CH}_{3} \mathrm{MgL}_{2}\right]^{-}(\mathrm{L}=\mathrm{CI}$ and $\mathrm{O}_{2} \mathrm{CCH}_{3}$ ): From Ligand Effects to Catalysis. J. Am. Chem. Soc. 2004, 126, 12173-12183.

17. Izquierdo, J.; Lopez, I.; Rodriguez, S.; Gonzalez, F. Epoxides as Useful Synthetic Building Blocks. Recent Res. Develop. Org. Chem. 2006, 10, 53-61.

18. Concellón, J. M.; Suárez, J. R.; García-Granda, S.; Díaz, M. R. Totally Selective Ring-Opening of Amino epoxides with Ketones: A General Entry to Enantiopure (2R,3S)- and (2S,3S)-3-Aminoalkano-1,2-Diols. Org. Lett. 2005, 7, 247-250.

19. Solladie-Cavallo, A.; Roje, M.; Giraud-Roux, M.; Chen, Y.; Berova, N.; Sunjic, V. Trans-Diaryl Epoxides: Asymmetric Synthesis Ring-Opening, and Absolute Configuration. Chirality 2004, 16, 196-203.

20. Meerwein H. Organic Ionic Reactions. Angew. Chem. 1955, 67, 374-380.

21. Moraes, L. A. B.; Eberlin, M. N. The Gas-Phase Meerwein Reaction. Chem. Eur. J. 2000, 6, 897-905.

22. Meurer, E. C.; Chen, H.; Riter, L. S.; Cooks, R. G.; Eberlin, M. N. Meerwein Reaction of Phosphonium Ions with Epoxides and Thioepoxides in the Gas Phase. J Am. Soc. Mass Spectrom. 2004, 15, 398-405.

23. Meurer, E. C.; Eberlin, M. N. The Atmospheric Pressure Meerwein Reaction. J. Mass Spectrom. 2006, 41, 470-476.

24. Chen, H.; Zheng, X.; Cooks, R. G. Ketalization of Phosphonium Ions by 1,4-Dioxane: Selective Detection of the Chemical Warfare Agent Simulant DMMP in Mixtures Using Ion/Molecule Reactions. J Am. Soc. Mass Spectrom. 2003, 14, 182-188.

25. Müller, L.; Mauthe, R. J.; Riley, C. M.; Andino, M. M.; De Antonis, D.; Beels, C.; Degeorge, J.; De Knaep, J. A. G. M.; Ellison, D.; Fagerland, J. A.; Frank, R.; Fritschel, B.; Galloway, S.; Harpur, E.; Humfrey, C. D. N.; Jacks, A. S.; Jagota, N.; Mackinnon, J.; Mohan, G.; Ness, D. K.; O'Donovan, M. R.; Smith, M. D.; Vudathala, G.; Yotti, L. A Rationale for
Determining, Testing, and Controlling Specific Impurities in Pharmaceuticals that Possess Potential for Genotoxicity. Regul. Toxicol. Pharm. 2006, 44, 198-211.

26. Guo, Y.; Breeden, L. L.; Fan, W.; Zhao, L. P.; Eaton, D. L.; Zarbl, H. Analysis of Cellular Responses to Aflatoxin B1 in Yeast Expressing Human Cytochrome P450 1A2 Using cDNA Microarrays. Mutat. Res. 2006, 593, 121-142.

27. Genotoxic and Carcinogenic Impurities in Drug Substances and Products: Recommended Approaches, U.S. Department of Health and Human Services, Food and Drug Administration, Center for Drug Evaluation and Research (CDER): Silver Spring, MD, U.S.A. 2008. http:// www.fda.gov/downloads/Drugs/Guidance-ComplianceRegulatory Information/Guidances/ucm079235.pdf

28. Liu, D. Q.; Wu, L.; Sun, M.; MacGregor, P. A. On-line H/D Exchange LC-MS Strategy for Structural Elucidation of Pharmaceutical Impurities. J. Pharm. Biomed. Anal. 2007, 44, 320-329.

29. Parr, R. G. Yang, W. Density-Functional Theory of the Electronic Structure of Molecules. Annual Rev. Phys. Chem. 1995, 46, 701-728.

30. Namazian, M.; Coote, M. L. G3 Calculations of the Proton Affinity and Ionization Energy of Dimethyl Methylphosphonate. J. Chem. Thermodynamics 2008, 40, 1116-1119.

31. Frisch, M. J.; Trucks, G. W.; Schlegel, H. B.; Scuseria, G. E.; Robb, M. A. Cheeseman, J. R.; Zakrzewski, V. G.; Montgomery, J. A.; Stratmann, R. E.; Burant, J. C.; Dapprich, S.; Millam, J. M.; Daniels, A. D.; Kudin, K. N.; Strain, M. C.; Farkas, O.; Tomasi, J.; Barone, V.; Cossi, M.; Cammi, R.; Mennucci, B.; Pomelli, C.; Adamo, C.; Clifford, S.; Ochterski, J.; Petersson, G. A.; Ayala, P. Y.; Cui, Q.; Morokuma, K.; Malick, D. K. Rabuck, A. D.; Raghavachari, K.; Foresman, J. B.; Cioslowski, J.; Ortiz J. V.; Baboul, A. G.; Stefanov, B. B.; Liu, G.; Liashenko, A.; Piskorz, P.; Komaromi, I.; Gomperts, R.; Martin, R. L.; Fox, D. J.; Keith, T.; Al-Laham, M. A.; Peng, C. Y.; Nanayakkara, A.; Gonzalez, C.; Challacombe, M. Gill, P. M. W.; Johnson, B.; Chen, W.; Wong, M. W.; Andres, J. L.; Gonzalez, C.; Gordon, H.-M.; Replogle, E. S.; Pople, J. A. Gaussian 03; Gaussian, Inc.: Pittsburgh PA, 2003.

32. Williams, T. I.; Denault, J. W.; Cooks, R. G. Proton Affinity of Deuterated Acetonitrile Estimated by the Kinetic Method with Full Entropy Analysis. Int. J. Mass Spectrom. 2001, 210/211, 133-146.

33. Mecozzis, S.; West, A. P.; Dougherty, D. A. Cation- $\pi$ Interactions in Aromatics of Biological and Medicinal Interest: Electrostatic Potential Surfaces as a Useful Qualitative Guide. Proc. Natl. Acad. Sci. U.S.A. 1996, 93, 10566-10571.

34. Wu, L.; Hernandez-Soto, H. Liu, D. Q; Vogt, F. G.; O'Neill-Slawecki, S. A.; Su, Q. Tandem Mass Spectrometry and Hydrogen/Deuterium Exchange Studies of Protonated Species of 1,10-Bis(Diphenylphosphino)Ferrocene Oxidative Impurity Generated During a Heck Reaction. Rapid Commun. Mass Spectrom. 2008, 22, 314-320.

35. Cheng, C.; Gross, M. L. Applications and Mechanisms of ChargeRemote Fragmentation. Mass Spectrom. Rev. 2000, 19, 398-420.

36. Elder, D. P.; Snodin, D.; Teasdale, A. Analytical Approaches for the Detection of Epoxides and Hydroperoxides in Active Pharmaceutical Ingredients, Drug Products, and Herbals. J. Pharm. Biomed. Anal. 2010, 51, 1015-1023.

37. Bai, L.; Sun, M.; An, J.; Liu, D. Q.; Chen, T. K.; Kord, A. S. Enhancing the Detection Sensitivity of Trace Analysis of Pharmaceutical Genotoxic Impurities by Chemical Derivatization and Coordination Ion SprayMass Spectrometry. J. Chromatogr. A 2010, 1217, 302-306. 